\title{
Ruxolitinib for essential thrombocythemia?
}

Editorial

\section{Prithviraj Bose and Srdan Verstovsek}

Essential thrombocythemia (ET) is the most indolent of the classic Philadelphia chromosome negative ( $\mathrm{Ph}-)$ myeloproliferative neoplasms (MPN), characterized by prolonged survival and low rates of progression to post-ET myelofibrosis (post-ET MF) and leukemic transformation. [1] As such, therapy for patients with ET focuses on the prevention of thrombo-hemorrhagic complications. The revised International Prognostic Score for ET (IPSET) - thrombosis model divides patients with ET into four thrombotic risk categories: very low, low, intermediate and high, based on age, presence or absence of the $J A K 2^{\text {V617F }}$ mutation and a history of thrombosis.[2] Cytoreductive therapy is generally recommended for patients at intermediate or high risk,[2] and hydroxyurea (HU) is typically the agent of choice. Anagrelide or interferon is usually chosen as second-line therapy in patients who fail $\mathrm{HU}$, although either agent may also be used upfront. A formal definition of resistance/intolerance to $\mathrm{HU}$ in patients with ET exists[3], however, this does not address the frequently encountered issue of persistent symptoms despite adequate control of hematologic parameters.

The Janus kinase $1 / 2$ inhibitor ruxolitinib is currently approved for the treatment of patients with myelofibrosis (MF), as well as for HU-resistant/intolerant patients with polycythemia vera (PV). The results of long-term followup of 39 patients with ET refractory to or intolerant of $\mathrm{HU}$ who were enrolled in a single-arm, non-comparative phase 2 clinical trial of ruxolitinib were recently published.[4] The median platelet and leukocyte counts and hemoglobin levels decreased over the first 4-8 weeks of therapy and stabilized thereafter. Of 22 patients with baseline platelet counts $>400 \times 10^{9} / \mathrm{L}$, all of whom received a starting dose of $25 \mathrm{mg}$ twice daily (bid) of ruxolitinib, the numbers achieving platelet counts $\leq 400 \times 10^{9} / \mathrm{L}$ were rather modest. However, when considering the 20 patients with baseline platelets $>600 \times 10^{9} / \mathrm{L}$, the proportions achieving platelet counts $\leq 600 \times 10^{9} / \mathrm{L}$ were $55 \%, 40 \%$ and $45 \%$ at weeks 12,48 and 312 , respectively. The median leukocyte count fell from $8.15 \times 10^{9} / \mathrm{L}$ at baseline to $5.2 \times 10^{9} / \mathrm{L}$ by 4 weeks of treatment, and remained within normal limits thereafter $\left(\sim 5-8 \times 10^{9} / \mathrm{L}\right)$. Most evaluable patients derived significant benefit in terms of ET-related symptoms by week 12 of therapy. The median change in the $J A K 2^{V 617 F}$ allele burden was only $-2.8 \%$ at 24 weeks, but the response deepened considerably over time, reaching a median of $-60 \%$ at week 312 . There were two thrombotic and four hemorrhagic events on study among the 22 patients who started ruxolitinib at a dose of $25 \mathrm{mg}$ bid. Two of these patients developed grade $\geq 3$ infections, while three had herpes zoster (all grades 1/2).

The MAJIC trial, the ET arm of which was also recently published[5], was a randomized controlled trial $(\mathrm{RCT})$ that compared ruxolitinib $(\mathrm{n}=58)$ to best available therapy (BAT, $\mathrm{n}=52$ ) in 110 ET patients resistant to or intolerant of HU. The study found no significant differences between the two arms in terms of complete hematologic response (CHR) rates, rates of thrombosis, hemorrhage, transformation, treatment discontinuation or switching; however, patients receiving ruxolitinib experienced greater symptom improvement than those assigned to BAT.

Although normalization of the platelet count is the goal of cytoreductive therapy in ET, there is no good evidence that platelet counts at baseline or during followup correlate with thrombotic risk; indeed, in one study of 891 patients with World Health Organization-defined ET, a platelet count $>1000 \times 10^{9} / \mathrm{L}$ at baseline was associated with a lower risk of arterial thrombosis.[6] Baseline leukocytosis $>11 \times 10^{9} / \mathrm{L}$ predicted arterial, but not venous, thrombosis in this study.[6] A significant association was reported between abnormal platelet counts during followup and an immediate risk of major hemorrhage (but not thrombosis) in an analysis of the prospective PT-1 cohort $(\mathrm{n}=776)$.[7] Leukocytosis during follow-up correlated with the occurrence of both thrombosis and major bleeding in this study.[7] The ongoing US pivotal RCT (see Table 1) of ruxolitinib versus anagrelide in patients with ET resistant to or intolerant of $\mathrm{HU}$ requires leukocyte and platelet counts at screening of $>11 \times 10^{9} / \mathrm{L}$ and $>650$ x $10^{9} / \mathrm{L}$, respectively.

Patients with ET have a substantial symptom burden, with $72 \%$ reporting fatigue and $\geq 40 \%$ reporting itching, night sweats and bone pain in one large internetbased survey $(\mathrm{n}=304)$. [8] Given that ruxolitinib, highly effective in controlling symptoms in patients with MF and PV through suppression of cytokines, is not currently approved for patients with ET, the treatment of symptomatic patients with ET who fail standard therapies remains an area of unmet need. Unfortunately, neither the ongoing registration trial in the US of ruxolitinib (NCT03123588) nor the second-line trial ongoing in Europe (NCT02962388) permit the enrollment of patients with uncontrolled symptoms on $\mathrm{HU}$, unless conventional criteria for resistance/intolerance[3] are met. The RUXO- 


\section{Table 1: Ongoing comparative clinical trials evaluating ruxolitinib in adults with essential}

thrombocythemia

\begin{tabular}{|l|l|l|l|l|l|}
\hline $\begin{array}{l}\text { Clinicaltrials.gov } \\
\text { identifier }\end{array}$ & Other name & Phase & Sponsor & Comparator & $\begin{array}{l}\text { Major eligibility } \\
\text { criteria }\end{array}$ \\
\hline NCT03123588 & RESET-272 & 2 & $\begin{array}{l}\text { Incyte } \\
\text { Corporation }\end{array}$ & Anagrelide & $\begin{array}{l}\text { HU resistance or } \\
\text { intolerance; [3] } \\
\text { platelets }>650 \times 10^{9} / \mathrm{L} \\
\text { and leukocytes }>11 \mathrm{x} \\
10^{9} / \mathrm{L} \text { at screening }\end{array}$ \\
\hline NCT02962388 & RUXBETA & $2 / 3$ & $\begin{array}{l}\text { French } \\
\text { Innovative } \\
\text { Leukemia } \\
\text { Organization }\end{array}$ & $\begin{array}{l}\text { Anagrelide } \\
\text { or interferon } \\
\text { alfa (can be } \\
\text { pegylated) }\end{array}$ & $\begin{array}{l}\text { Patients with } \\
\text { high risk ET and } \\
\text { HU resistance or } \\
\text { intolerance[3] }\end{array}$ \\
\hline NCT02577926 & Ruxo-BEAT & 3 & $\begin{array}{l}\text { RWTH Aachen } \\
\text { University }\end{array}$ & $\begin{array}{l}\text { Best available } \\
\text { therapy }\end{array}$ & $\begin{array}{l}\text { Treatment-naïve or } \\
\text { previously treated } \\
\text { patients who } \\
\text { are }>60 \text { or have } \\
\text { platelets }>1500 \mathrm{x} \\
10^{9} / \mathrm{L}, \text { or h/o prior } \\
\text { thromboembolism } \\
\text { or ET-related severe } \\
\text { hemorrhage }\end{array}$ \\
\hline
\end{tabular}

Abbreviations: ET, essential thrombocythemia; HU, hydroxyurea.

BEAT trial (NCT02577926) in Germany comparing ruxolitinib to BAT does allow the enrollment of both treatment-naïve and previously treated patients with ET as long as $\geq 1$ high risk features (age $>60$, platelets $>1500$ $\mathrm{x} 10^{9} / \mathrm{L}$, previous thrombosis or severe hemorrhage related to ET) are present.

Potential concerns surrounding the use of ruxolitinib in patients with an indolent condition like ET include cost of therapy and long-term infectious risk, although the latter is not a major concern based on the experience to date in $\mathrm{MF}$ and $\mathrm{PV}$. While driver mutation allele burden reduction over time, also seen in PV, is intuitively appealing, the significance of this is poorly understood, e.g., progression of ET to MF despite attainment of complete molecular response was reported in the MAJIC trial.[5]

\section{CONFLICTS OF INTEREST}

P.B. discloses no potential conflicts of interest relevant to this manuscript within 12 months. S.V. discloses research support from: Incyte Corporation, Roche, Astrazeneca, Lilly Oncology, NS Pharma, Bristol Myers Squibb, Celgene, Gilead, Seattle Genetics, Promedior, CTI BioPharma Corp.,Galena BioPharma, Pfizer, Genentech, and Blueprint Medicines Corp.
Prithviraj Bose: Department of Leukemia, UT MD Anderson Cancer Center, Houston, TX, USA

Correspondence: Prithviraj Bose, email pbose@mdanderson.org

Keywords: essential thrombocythemia; ruxolitinib; JAK inhibitor; symptoms; platelet count; leukocyte count

Received: October 25, 2017

Published: November 01, 2017

\section{REFERENCES}

1. Tefferi A, et al. Blood. 2014; 124: 2507-13; quiz 2615

2. Barbui T, et al. Blood cancer journal. 2015; 5: e369

3. Barosi G, et al. Leukemia. 2007; 21: 277-280

4. Verstovsek S, et al. Blood. 2017; 130: 1768-1771

5. Harrison $\mathrm{CN}$, et al. Blood. 2017

6. Carobbio A, et al. Blood. 2011; 117: 5857-5859

7. Campbell PJ, et al. Blood. 2012; 120: 1409-1411

8. Mesa RA, et al. Cancer. 2007; 109: 68-76

Copyright: Bose et al. This is an open-access article distributed under the terms of the Creative Commons Attribution License 3.0 (CC BY 3.0), which permits unrestricted use, distribution, and reproduction in any medium, provided the original author and source are credited. 